\title{
MULTI CRITERIA EVALUATION FRAMEWORK FOR PRIORITIZING INDIAN RAILWAY STATIONS USING MODIFIED ROUGH AHP-MABAC METHOD
}

\author{
Haresh Kumar Sharma ${ }^{1}$, Jagannath Roy ${ }^{2}$, Samarjit Kar,", Olegas Prentkovskis ${ }^{4}$ \\ ${ }^{I}$ Department of Mathematics, National Institute of Technology Durgapur, India; \\ hks.14ma1106@phd.nitdgp.ac.in \\ ${ }^{2}$ Department of Mathematics, National Institute of Technology Durgapur, India; \\ jr.13math1101@phd.nitdgp.ac.in \\ ${ }^{3}$ Department of Mathematics, National Institute of Technology Durgapur, India; \\ samarjit.kar@maths.nitdgp.ac.in \\ ${ }^{4}$ Department of Mobile Machinery and Railway Transport, Faculty of Transport Engineering, Vilnius \\ Gediminas Technical University, Vilnius, Lithuania; olegas.prentkovskis@vgtu.lt
}

\begin{abstract}
This study proposes a hybrid multiple criteria decision making (MCDM) methodology for evaluating the performance of the Indian railway stations (IRS). Since the customers are heterogeneous and their requirements are often imprecise, the evaluation process is a critical step for prioritizing the IRS. To improve the existing approaches, an efficient evaluation technique has been proposed by integrating rough numbers, analytic hierarchy process (AHP) and multi-attribute border approximation area comparison (MABAC) methods in rough environment. The relative criteria weights based on their preferences given by experts is determined by rough AHP whereas evaluation of the alternatives based on these criteria are done by the modified rough MABAC method. A case study of prioritizing different railway stations in India is provided to demonstrate the efficiency and applicability of the proposed method. Among different criteria "proactively" is observed to be the most important criteria in our analysis, followed by "Railfanning' and 'DMO' is found to be the best among the forty IRS in this study. Finally, a comparative analysis and validity testing of the proposed method are elaborated and the methodology provides a standard to select IRS on the basis of different criteria.
\end{abstract}

Keywords: Multiple criteria decision making, rough number; AHP; MABAC; Smart railway stations

\section{Introduction}

Indian Railways is one of the essential sectors that have a major impact on the economic growth of an India. IR owned and operated by the Government of India. Rail is an important part of connectivity or communication in India. It's also an important part of freight transfer compared to other modes of goods transfer. First of all, the development of the railway station is very important for the railway's profit. Railway stations are the points where the people get down or get into and goods are loaded or unloaded. There are various characteristics like safety, cleanliness, etc. which determine the success of this institution to a great extent (Givoni and Rietveld, 2014). In principle, every excellent station enhances the attraction of IRs. In Large cities like Mumbai, Kolkata, Delhi, etc. have other modes of railway transport like metro or mono rail in addition to the extra stations used to serve the large population. Maintenance of the facilities at the railway station is a big challenge for the Indian Ministry of Railways. The government of India is preparing an ambitious plan for the beautification of railway stations, through this scheme, and they are insisting on making all the important stations as a smart station. The parameters that influence this government's plan mostly are safety, cleanliness, etc. Hence, to upgrade the railway station facilities it is the prerequisite to understand the assignment for proper planning procedure. The present study aims to analyze smart railway stations through improvement in the service quality of considered parameters.

Here, we need to discuss the background of the method to solve uncertain MCDM problems. In general, the professionals' judgments own subjective uncertainty in addition to impreciseness because of verbal evaluation which results in non-probabilistic traits (Martínez et al., 2007). The fuzzy set theory has been studied in various dimensions to handle actual life inaccurate hitches (Roy et al., 2016a, 2016b; Chen, 2000). Fuzzy methodology tackles the inaccuracy very efficiently, but it requires very previous data or strong association element to result in an effective decision at a particular interval of described time (Qazi et al., 2016; Wang et al., 2016; Roy et al., 2018). Rough set theory use to alter the roughness of a data, which has been successfully applied to various real life decision making problems (Pawlak, 1991; Pawlak, 1982; Zheng et al., 2016; Zhai et al., 2010; Khoo and Zhai, 2001; Liang et al., 2016). Rough numbers are used to represent the roughness in decision-making task that eliminate the 
obstructions of conceptual rough set methodology and directly come up with a decision via original data, hence it becomes a lot easier than fuzzy set theory (Pawlak, 1991). Therefore the structure of provided data is more important than any surplus factor, in the application of rough numbers (Zhu et al., 2015).

Limited number of research work are available for evaluation and ranking of railways performance. Rietveld (2000) perform a study on Role of bicycle to access railway station: Case study of Netherlands. Daamen (2002) performed quantitative assessment to analyze railway station's design followed by Kaakai et al. (2007) used Hybrid Petri nets model to evaluate railways transit station's design. Givoni and Rietveld (2007) applied regression analysis in Netherland's railway station data to analyze passengers' satisfaction. Mateus et al. (2008) applied multi-criteria decision analysis to select best location alternative of railway station in Central Porto. Subsequently, Brons et al. (2009) applied principal component analysis in passenger's survey data to determine service performance of railway station. Mohajeri and Amin (2010) used analytic hierarchy process (AHP) and data envelopment analysis (DEA) to find the best location for the railway station. Later, Zemp et al. (2011) applied statistical analysis on Swiss railway station data for strategic transport purpose. In the same year, Lai and Chen (2011) analysed railways passenger's behaviours to improve factors like service quality, satisfaction, and perceived value using structural equation modelling technique.

Most of the research works related to railways development and management are based on crisp data or limited to fuzzy approaches which need much prior data. Many authors (Roy et al. 2018; Zhai et al., 2008, 2009) have asserted the superiority of rough numbers over fuzzy approaches in manipulating subjective and vague information. To the best of our knowledge, till date, we have not found any article or research paper which investigated railways problems using such a technique deals uncertainty. The main objectives and the major contribution of this research work are listed below:

- To develop the methods (modified rough AHP and MABAC) required to treat the uncertainty in the context of multi criteria decision making environment.

- To propose a comprehensive and systematic evaluation for framework to handle uncertainty in realistic problems.

- To analyze passengers' preferences for station master, divisional railway manager (DRM), ministry of railway (MoR) and investors in railways who need deep investigations to identify the critically important factors for further development.

- To assist the IRs to make decisions based on more effective indicators of high-quality services for a higher rate of satisfaction.

The rest of the paper is organized as follows. Section 2 introduces the basic concepts of rough numbers with arithmetic operations, AHP and MABAC methods. Section 3 proposes a framework of the proposed hybrid AHP-MABAC method based on rough number. A case study on ranking of railway stations in Indian perspective is discussed along with comparative analysis and validity testing of proposed method in Section 4. Section 5 deals with the major implications of this study. Finally, section 6 summarises the major benefits, limitations and future directions of this research work.

\section{Preliminaries on rough number}

Rough number (Zhai et al., 2008) based on rough set theory was developed in determining the boundary interval to handle subjective judgment of decision makers. It was further integrated with interval arithmetic operations to analyse vague information (Zhai et al., 2009). A rough number with lower, upper and boundary interval respectively, does not require any subjective adjustment to analyse data. Unifying rough number in concept evaluation structure, decision makers will give rational decisions in the subjective situation. Assume that $\Lambda$ is the universe of all the objects, $X$ be an arbitrary object of $\Lambda$ and $E$ be a set of $t$ classes that covers all objects in $\Lambda$. i.e., $E=\left\{\mathcal{G}_{1}, \mathcal{G}_{2}, \cdots, \mathcal{G}_{t}\right\}$, then $\mathcal{G}_{q} \in E, \forall X \in \Lambda$, $1 \leq q \leq t$, provided $\mathcal{G}_{1},<\mathcal{G}_{2}<\cdots<\mathcal{G}_{t}$. The lower approximation $\left(\operatorname{Apr}\left(\mathcal{G}_{q}\right)\right)$, upper approximation $\left(\overline{\operatorname{Apr}}\left(\mathcal{G}_{q}\right)\right)$ and boundary region $\left(B n d\left(\mathcal{G}_{q}\right)\right)$ of class $\mathcal{G}_{q}$ are defined as:

$$
\begin{aligned}
& \overline{\operatorname{Apr}}\left(\mathcal{G}_{q}\right)=\bigcup\left\{X \in \Lambda: E(X) \leq \mathcal{G}_{q}\right\}, \\
& \overline{\operatorname{Apr}}\left(\mathcal{G}_{q}\right)=\bigcup\left\{X \in \Lambda: E(X) \geq \mathcal{G}_{q}\right\}, \\
& \operatorname{Bnd}\left(\mathcal{G}_{q}\right)=\bigcup\left\{X \in \Lambda: E(X) \neq \mathcal{G}_{q}\right\}=\left\{X \in \Lambda: E(X)<\mathcal{G}_{q}\right\} \cup\left\{X \in \Lambda: E(X)>\mathcal{G}_{q}\right\} .
\end{aligned}
$$

Then class $\mathcal{G}_{q}$ denoted by $R N\left(\mathcal{G}_{q}\right)$ with corresponding lower and upper limits $\left(\left(\underline{\operatorname{Lim}}\left(\mathcal{G}_{q}\right)\right),\left(\overline{\operatorname{Lim}}\left(\mathcal{G}_{q}\right)\right)\right.$ as follows: 


$$
\begin{aligned}
& R N\left(\mathcal{G}_{q}\right)=\left[\underline{\operatorname{Lim}}\left(\mathcal{G}_{q}\right), \overline{\operatorname{Lim}}\left(\mathcal{G}_{q}\right)\right], \\
& \underline{\operatorname{Lim}}\left(\mathcal{G}_{q}\right)=\frac{1}{M_{L}} \sum E(X) \mid X \in \underline{\operatorname{Apr}}\left(\mathcal{G}_{q}\right), \\
& \overline{\operatorname{Lim}}\left(\mathcal{G}_{q}\right)=\frac{1}{M_{U}} \sum E(X) \mid X \in \overline{\operatorname{Apr}}\left(\mathcal{G}_{q}\right),
\end{aligned}
$$

where $M_{L}, M_{U}$ are the number of objects included in $\operatorname{Apr}\left(\mathcal{G}_{q}\right)$ and $\overline{\operatorname{Apr}}\left(\mathcal{G}_{q}\right)$ respectively. The lower limit, $\underline{\operatorname{Lim}}\left(\mathcal{G}_{q}\right)$ and the upper limit, $\overline{\operatorname{Lim}}\left(\mathcal{G}_{q}\right)$, denote the mean value of elements included in its corresponding lower and upper approximation, respectively, with their difference denoted as rough boundary interval $\operatorname{IRBnd}\left(\mathcal{G}_{q}\right)$, defined by Eq. (7).

$\operatorname{IRBnd}\left(\mathcal{G}_{q}\right)=\overline{\operatorname{Lim}}\left(\mathcal{G}_{q}\right)-\underline{\operatorname{Lim}}\left(\mathcal{G}_{q}\right)$.

Aggregation, arithmetic operations and comparison of rough numbers can be found in Roy et al. (2018), Zhai et al. (2008, 2009).

\section{Proposed Methodology}

In this section, the detailed procedures of modified rough AHP based rough MABAC method have been given.

\subsection{Modified rough AHP model for criteria weighting:}

Step 1. Establishing a hierarchical structure of evaluation criteria: A group of experts is formed who carry out the selection criteria and define a problem hierarchy with global goals at the upper and lower level criteria.

Step 2. Filling a matrix to compare evaluation criteria in pairs: Members of the group of experts compare in pairs the evaluation criteria in order to define the criteria weights. Comparison in pairs is done using the Saaty ninth degree linguistic scale. Each $k$-th expert presents his/her comparisons by using matrix:

$Z_{k}=\left(z_{i j}^{k}\right)_{n \times n} \quad(1 \leq k \leq K)$,

where $z_{i j}^{k}=1$ if $i=j$ and are phrases from Saaty ninth degree linguistic scale used by expert $k$ to present his/her comparison in criteria pairs. Thus, $Z_{1}, Z_{2}, \ldots, Z_{K}$ are the matrices provided by $K$ experts for $i$ th criterion compared with $j$ th criterion.

Step 3. Determination of experts' weight coefficients: For each comparison matrix $Z_{k}$ is determined by the consistency of experts' evaluation. Saaty suggested the consistency ratio $(C R)$ for the consistency check. The calculation of the degree of consistency is done in two steps. In the first step, the consistency index $(C I)$ is calculated as $C I=\left(\lambda_{\max }^{k}-1\right) /(n-1)$, where $n$ is matrix rank and $\lambda_{\max }$ is the maximum Eigen value of the comparison matrix. The second step calculates $C R$ as the ratio between $C I$ and the random index $(R I)$.

$C R=\frac{C I}{R I}$.

The random index (RI) depends on matrix rank, and its values are calculated with the random generation of 500 matrices; see Table 1.

Table 1. Random Index (RI) (Saaty and Vargas, 2012)

\begin{tabular}{ccccrrrrr}
\hline$n$ & 3 & 4 & 5 & 6 & 7 & 8 & 9 & 10 \\
\hline RI & 0.52 & 0.89 & 1.11 & 1.25 & 1.35 & 1.40 & 1.45 & 1.49 \\
\hline
\end{tabular}

If the consistency ratio (CR) is less than or equal to 0.10 , which proves that the expert was consistent and there is no need to repeat the evaluations. If the CR is higher than 0.10 , the decision-maker should repeat (or modify) his/her evaluation in order to improve his/her own consistency.

Step 4. Construction of the average interval rough comparison matrix: Using Matrix (10) from all $K$ experts, the matrix of aggregated experts' sequences are obtained.

$Z=\left(\left\{z_{i j}^{1}, z_{i j}^{2}, \cdots, z_{i j}^{K}\right\}\right)_{n \times n}$, 
where $z_{i j}=\left\{z_{i j}^{1}, z_{i j}^{2}, \cdots, z_{i j}^{K}\right\}$ is the sequence used to describe the relative significance of criterion $i$ towards criterion $j$. Using equations (1)-(7), each sequence $\left(z_{i j}^{k} ; 1 \leq k \leq K\right)$ is transformed into rough sequence $R N\left(z_{i j}^{k}\right)=\left[z_{i j}^{k L}, z_{i j}^{k U}\right]$. Note that, $z_{i j}=\left\{z_{i j}^{1}, z_{i j}^{2}, \cdots, z_{i j}^{K}\right\}=\{1,1, \ldots, 1\}$ if $i=j$.

Step 5. Eqs. (1)- (7), translate the element $z_{i j}$ in group decision matrix $Z$ into $R N\left(z_{i j}^{k}\right)$ of $z_{i j}$ as:

$R N\left(z_{i j}^{k}\right)=\left[z_{i j}^{k L}, z_{i j}^{k U}\right]$,

where $z_{i j}^{k L}$ the lower limit and $z_{i j}^{k U}$ the upper limit of rough number $R N\left(z_{i j}^{k}\right)$ in $k$ th pair-wise comparison matrix respectively.

Then we obtain a rough sequence $R N\left(z_{i j}\right)$ represented in (12) as:

$R N\left(z_{i j}\right)=\left\{\left[z_{i j}^{1 L}, z_{i j}^{1 U}\right],\left[z_{i j}^{2 L}, z_{i j}^{2 U}\right], \ldots,\left[z_{i j}^{K L}, z_{i j}^{K U}\right]\right\}$.

The average rough interval $\overline{R N\left(z_{i j}\right)}$ is obtained by using equations (13) and (14):

$\overline{R N\left(z_{i j}\right)}=\left[z_{i j}^{L}, z_{i j}^{U}\right]$

$z_{i j}^{L}=1 / K \sum_{k=1}^{K} s_{k} \cdot z_{i j}^{k L}$ and $z_{i j}^{U}=1 / K \sum_{k=1}^{K} s_{k} \cdot z_{i j}^{k U}$.

Here $z_{i j}^{L}$ and $z_{i j}^{U}$ represent the lower and upper limits of the aggregated rough number and $s_{k}$ is the weight priorities assigned to DMs satisfying the condition, $\sum_{k=1}^{K} s_{k}=1$.

Then the rough group decision matrix $M$ is formed as follows:

$M=\left(\left[z_{i j}^{L}, z_{i j}^{U}\right]\right)_{n \times n}$.

Step 6. Calculate the rough based weight $W_{i}$ of each criterion:

$W_{i}=\left(\left[W_{i}^{L}, W_{i}^{U}\right]\right)=\left(\left[\left(\prod_{j=1}^{n} z_{i j}^{L}\right)^{1 / n},\left(\prod_{j=1}^{n} z_{i j}^{U}\right)^{1 / n}\right]\right)$

and its normalized counterparts $\left(W_{i}\right)$ by the following equation (17)

$W_{i}=\left[W_{i}^{L}, W_{i}^{U}\right]=\left[\frac{W_{i}^{L}}{\max \left(W_{i}^{U}\right)}, \frac{W_{i}^{U}}{\max \left(W_{i}^{U}\right)}\right] ; \quad i=1,2, \ldots, n$.

\subsection{Modified rough number based MABAC for evaluating alternatives}

Here, we extend the concept of MABAC to develop a rough number-based MCDM framework for evaluating alternatives railway station against some criteria whose weight coefficients are obtained by rough AHP method as discussed in section 3.1. The steps of rough MABAC are as follows.

Step 1. Collect the individual decision matrix $\left(X_{k}\right)$ from each decision experts in the form of equation (18). Applying the rough number method (described in section 2) we quantify the experts' ratings and obtain the group rough number based decision matrix as defined by equation (20).

$X_{k}=\left(x_{i j}^{k}\right)_{m \times n}$,

$\tilde{X}=\left(\left\{x_{i j}^{1}, x_{i j}^{2}, \ldots, x_{i j}^{K}\right\}\right)_{m \times n}$,

$X=\left(\left[x_{i j}^{L}, x_{i j}^{U}\right]\right)_{m \times n}$,

where $\left[x_{i j}^{L}, x_{i j}^{U}\right]$ being the value of the $i$-th alternative as per $j$-th criterion, $\mathrm{m}$ denotes the number of alternatives and $\mathrm{n}$ the number of criteria.

Step 2. Applying equations (21)-(24), the normalized rough decision matrix, $N=\left(\left[y_{i j}^{L}, y_{i j}^{U}\right]\right)_{m \times n}$ is computed from the initial matrix $(X)$.

(a) For Benefit type criteria

$y_{i j}^{L}=\left(x_{i j}^{L}-x_{j}^{-}\right) /\left(x_{j}^{+}-x_{j}^{-}\right)$and $y_{i j}^{U}=\left(x_{i j}^{U}-x_{j}^{-}\right) /\left(x_{j}^{+}-x_{j}^{-}\right)$.

(b) For Cost type criteria

$y_{i j}^{L}=\left(x_{i j}^{L}-x_{j}^{+}\right) /\left(x_{j}^{-}-x_{j}^{+}\right)$and $y_{i j}^{U}=\left(x_{i j}^{U}-x_{j}^{+}\right) /\left(x_{j}^{-}-x_{j}^{+}\right)$, 


$$
\begin{aligned}
& x_{j}^{+}=\left\{\begin{array}{lr}
\max _{1 \leq i \leq m}\left(x_{i j}^{U}\right), & \text { for benefit type criteria } \\
\min _{1 \leq i \leq m}\left(x_{i j}^{L}\right), & \text { for cost type criteria }
\end{array} \quad j=1,2, \ldots, n .\right. \\
& x_{j}^{-}=\left\{\begin{array}{lr}
\min _{1 \leq i \leq m}\left(x_{i j}^{L}\right), & \text { for benefit type criteria } \\
\max _{1 \leq i \leq m}\left(x_{i j}^{U}\right), & \text { for cost type criteria }
\end{array} \quad j=1,2, \ldots, n .\right.
\end{aligned}
$$

Step 3. In this step, the weighted rough decision making matrix $(V)$ is calculated using equation (25) as follows:

$V=\left(\left[v_{i j}^{L}, v_{i j}^{U}\right]\right)_{m \times n}$,

where $v_{i j}^{L}=W_{j}^{L} \cdot\left(y_{i j}^{L}+1\right), v_{i j}^{U}=W_{j}^{U} \cdot\left(y_{i j}^{U}+1\right)$, and $\left[W_{j}^{L}, W_{j}^{U}\right]$ the weight coefficients of the $j$ th criterion.

Step 4. Using the geometric aggregation for interval numbers $g_{j}=\left[g_{j}^{L}, g_{j}^{U}\right]$, border approximation area (BAA) for each criterion is calculated as per equation (26):

$G=\left[g_{1}, g_{2}, \ldots, g_{n}\right]_{1 \times n}$,

where $g_{j}^{L}=\left(\prod_{i=1}^{m} v_{i j}^{L}\right)^{1 / m}$ and $g_{j}^{U}=\left(\prod_{i=1}^{m} v_{i j}^{U}\right)^{1 / m}\left[v_{i j}^{L}, v_{i j}^{U}\right]$ are the elements of $V$.

Step 5. The Euclidean distance operator (Hennig et al., 2015) for interval numbers is used here for rough numbers to measure the distances of the alternatives from BAA for getting the distance matrix $Q$ as:

(c) $Q=\left(q_{i j}\right)_{m \times n}=\left(\left[q_{i j}^{L}, q_{i j}^{U}\right]\right)_{m \times n}$,

where $q_{i j}$ 's are calculated as follows:

- For maximizing criteria/benefit criteria

$q_{i j}= \begin{cases}d_{E}\left(v_{i j}, g_{j}\right), & \text { if } R N\left(v_{i j}\right)>R N\left(g_{j}\right) \\ 0, & \text { if } R N\left(v_{i j}\right)=R N\left(g_{j}\right), \\ -d_{E}\left(v_{i j}, g_{j}\right), & \text { if } R N\left(v_{i j}\right)<R N\left(g_{j}\right)\end{cases}$

- For minimizing criteria/cost criteria

$q_{i j}= \begin{cases}-d_{E}\left(v_{i j}, g_{j}\right), & \text { if } R N\left(v_{i j}\right)>R N\left(g_{j}\right) \\ 0, & \text { if } R N\left(v_{i j}\right)=R N\left(g_{j}\right), \\ d_{E}\left(v_{i j}, g_{j}\right), & \text { if } R N\left(v_{i j}\right)<R N\left(g_{j}\right)\end{cases}$

where

$d_{E}\left(v_{i j}, g_{j}\right)=\sqrt{\left(v_{i j}^{L}-g_{j}^{L}\right)^{2}+\left(v_{i j}^{U}-g_{j}^{U}\right)^{2}}$,

and $\left[g_{j}^{L}, g_{j}^{U}\right]$ is the border approximation area for criterion $C_{j}(j=1,2, \ldots, n)$.

Now, an alternative $A_{i}$ will belong to the BAA $(G)$ if $q_{i j}=0$, upper approximation area $\left(G^{+}\right)$if $q_{i j}>0$, and lower approximation area $\left(G^{-}\right)$if $q_{i j}<0$. The ideal alternative $\left(A^{+}\right)$can be found in the upper approximation area $\left(G^{+}\right)$whereas the lower approximation area $\left(G^{-}\right)$contains the anti-ideal alternative $\left(A^{-}\right)$. For alternative $A_{i}$ to be best, it is necessary to have as many criteria belonging to the upper approximation area $\left(G^{+}\right)$.

Step 6. Determine the ranking orders of all alternatives.

Alternative $A_{i}$ is near or equal to the ideal and anti-Ideal solution if the distance value $q_{i j} \in G^{+}$and $G^{-}$respectively. For criteria function values of the alternative sites, the distances of the alternatives from BAA vector are added. Summing row elements of matrix $(Q)$, final score values of the criterion functions for alternatives are obtained as (31):

$S\left(A_{i}\right)=\sum_{j=1}^{n} q_{i j}, i=1,2, \ldots, m$. 


\section{Case study from Indian railways}

This case study is conducted based on the related information/data about railway stations of India. IRS plays a major role in India's economic development. Maintaining the world-class standard of railway stations is an integral part for an overall development of IRS. Accordingly, improving the service quality of railway station is an utmost important task for the rail ministry. In the data collection phase of the IRS, the primary data is collected with the opinion of four different railways officers, these officers are fully responsible for the maintaining the standard of the railway station. Here, forty railway stations have been considered which are very much important from the perspective of trade and culture tourism.

In this study, some vital attributes related to railway stations including "cleanliness", "porter/escalators", "food", "transportation", "lodging", "railfanning", "sightseeing", "safety" and "proactively" have been considered and their respective feedbacks are reorder by inviting domain experts (railways officers). All experts have 20-25 years of work experience in various disciplines including Railway Protection Force (RPF), Research designs \& standards organisation (RDSO), Indian railway catering and tourism corporation (IRCTC), customer facility, control office and policy making. These experts pay their overarching focus on IRs with their momentous knowledge and supply the essential inputs which essentially become the foundation to carry out the research work. The evaluation/feedback is provided on a 10- point scale.

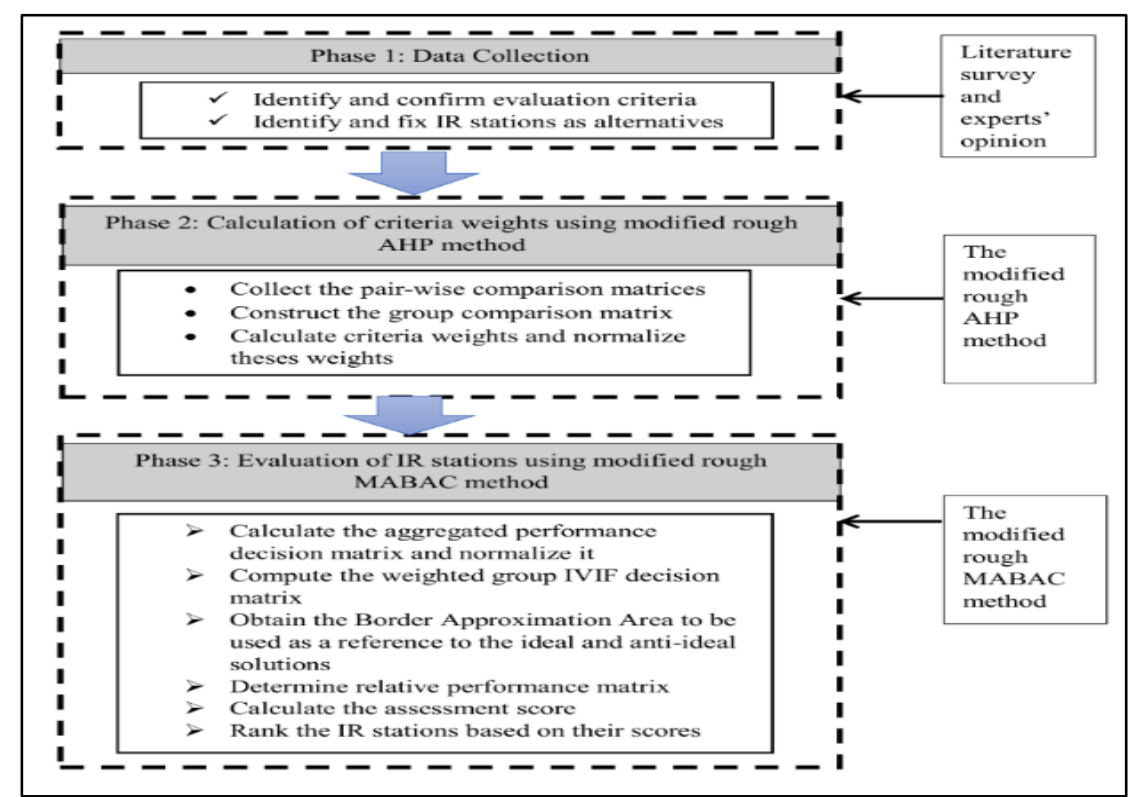

Figure 1. Flow diagram for implementing the modified rough AHP-MABAC method

IR targets to move passengers towards rails for increasing the utility of trains. IR wanted to serve the nation with proper safety. Although railways committed for the security of passengers they also attract more and more passengers and provide them better facility. In different words, the target to the IR is especially to facilitate the passengers, by way of making the ones facilities higher, the railways can entice new passengers and provide new instructions to the IR, through which the earnings may be introduced to the railways. After the above-mentioned analysis we conclude that firstly passengers must be satisfied by the facilities of rail journey as well as its access up to the reach of common people. By improving the arrival of trains on nearby stations is somehow increase its use. It is even more important for infrequent rail passengers. It indicates that if we boost the accessibility of rail network then its use may also be increased and it attracts new passengers too.

Table 2. Description of evaluation criteria

\begin{tabular}{|l|l|}
\hline Station criteria & Interpretation \\
\hline Cleanliness (C1) & According to the IR guidelines, the cleaning condition of a particular station. \\
Porters (C2) & A person who carrying luggage and parcel in railway station. \\
Food (C3) & Quality of food according to the standard of railway's guideline. \\
Transportation (C4) & Transit facility \\
Lodging (C5) & Accommodation facility in railway station, e.g. waiting room retiring, etc. \\
Rail-fanning (C6) & A passenger's feedback on a recreational capacity of a railway station. \\
Sightseeing (C7) & Visiting places nearby railway station. \\
Safety (C8) & Preventive measures to avoid danger, risk or injury in railway station. \\
Proactively (C9) & Controlling a situation by the railway station authority. \\
\hline
\end{tabular}


Table 3. Scale for measuring relative performances of alternatives and priority of criteria

\begin{tabular}{|l|l|}
\hline Scale/importance & Crisp value and STFN \\
\hline Very Low (VL) & $1[0,2]$ \\
\hline Very Low & $2[1,3]$ \\
\hline Low (L) & $3[2,4]$ \\
\hline Low & $4[3,5]$ \\
\hline Moderate (M) & $5[4,6]$ \\
\hline Moderate & $6[5,7]$ \\
\hline High $(\mathrm{H})$ & $7[6,8]$ \\
\hline High & $8[7,9]$ \\
\hline Very High $(\mathrm{VH})$ & $9[8,10]$ \\
\hline
\end{tabular}

\subsection{Implementation of modified rough AHP}

Firstly, build a group of four decision experts in railways and collect individual judgments of four decision makers and using of the rough AHP method, construct four non-negative pairwise comparison matrices and then calculate the consistency ratio of each judgment matrix. Note that, $\boldsymbol{C} \boldsymbol{R}^{\boldsymbol{e}}<\mathbf{0 . 1 0}$ for all $\boldsymbol{B}_{\boldsymbol{e}}(\boldsymbol{e}=\mathbf{1}, 2,3,4)$. So, all the pairwise comparison matrices are acceptable. The individual comparison matrices for four different experts are as follows.

\begin{tabular}{|c|c|c|c|c|c|c|c|c|c|c|c|c|c|c|c|c|c|c|}
\hline$[1$ & 3 & $1 / 5$ & 2 & 3 & $1 / 3$ & 1 & $1 / 3$ & $1 / 9$ & & {$[1$} & 3 & $1 / 5$ & 2 & 3 & $1 / 3$ & 1 & $1 / 3$ & $1 / 97$ \\
\hline $1 / 3$ & 1 & $1 / 7$ & $1 / 5$ & 1 & $1 / 7$ & $1 / 3$ & $1 / 5$ & $1 / 9$ & & $1 / 3$ & 1 & $1 / 7$ & $1 / 5$ & 1 & $1 / 4$ & $1 / 3$ & $1 / 4$ & $1 / 9$ \\
\hline 5 & 7 & 1 & 5 & 5 & 2 & 3 & 3 & $1 / 7$ & & 5 & 7 & 1 & 5 & 5 & 2 & 3 & 3 & $1 / 5$ \\
\hline $1 / 2$ & 5 & $1 / 5$ & 1 & 5 & $1 / 3$ & $1 / 2$ & $1 / 3$ & $1 / 7$ & & $1 / 2$ & 5 & $1 / 5$ & 1 & 5 & $1 / 3$ & $1 / 3$ & $1 / 3$ & $1 / 7$ \\
\hline$=1 / 3$ & 1 & $1 / 5$ & $1 / 5$ & 1 & $1 / 5$ & $1 / 5$ & $1 / 5$ & $1 / 7$ & $z^{2}=$ & $1 / 3$ & 1 & $1 / 5$ & $1 / 5$ & 1 & $1 / 5$ & $1 / 5$ & $1 / 5$ & $1 / 7$ \\
\hline 3 & 7 & $1 / 2$ & 3 & 5 & 1 & 5 & 5 & $1 / 3$ & & 3 & 4 & $1 / 2$ & 3 & 5 & 1 & 5 & 5 & $1 / 5$ \\
\hline 1 & 3 & $1 / 3$ & 2 & 5 & $1 / 5$ & 1 & $1 / 3$ & $1 / 7$ & & 1 & 3 & $1 / 3$ & 3 & 5 & $1 / 5$ & 1 & $1 / 3$ & $1 / 7$ \\
\hline 3 & 5 & $1 / 3$ & 3 & 5 & $1 / 5$ & 3 & 1 & $1 / 6$ & & 3 & 4 & $1 / 3$ & 3 & 5 & $1 / 5$ & 3 & 1 & $1 / 5$ \\
\hline 9 & 9 & 7 & 7 & 7 & 3 & 7 & 6 & 1 & & 9 & 9 & 5 & 7 & 7 & 3 & 7 & 5 & $1]$ \\
\hline$\lceil 1$ & 3 & $1 / 2$ & 2 & 3 & $1 / 3$ & 3 & $1 / 5$ & $1 / 7]$ & & {$[1$} & 3 & $1 / 3$ & 3 & 3 & $1 / 3$ & 3 & $1 / 5$ & $1 / 7$ \\
\hline $1 / 3$ & 1 & $1 / 7$ & $1 / 2$ & $1 / 2$ & $1 / 5$ & $1 / 3$ & $1 / 4$ & $1 / 9$ & & $1 / 3$ & 1 & $1 / 6$ & $1 / 2$ & $1 / 2$ & $1 / 5$ & $1 / 3$ & $1 / 4$ & $1 / 9$ \\
\hline $1 / 2$ & 7 & 1 & 3 & 5 & 2 & 1 & 1 & $1 / 5$ & & $1 / 3$ & 6 & 1 & 4 & 5 & 2 & 1 & 1 & $1 / 5$ \\
\hline $1 / 2$ & 2 & $1 / 3$ & 1 & 5 & $1 / 3$ & $1 / 3$ & $1 / 3$ & $1 / 9$ & & $1 / 3$ & 2 & $1 / 4$ & 1 & 5 & $1 / 3$ & $1 / 3$ & $1 / 3$ & $1 / 9$ \\
\hline $1 / 3$ & 2 & $1 / 5$ & $1 / 5$ & 1 & $1 / 6$ & $1 / 5$ & $1 / 5$ & $1 / 7$ & $Z^{4}=$ & $1 / 3$ & 2 & $1 / 5$ & $1 / 5$ & 1 & $1 / 7$ & $1 / 5$ & $1 / 5$ & $1 / 7$ \\
\hline 3 & 5 & $1 / 2$ & 5 & 6 & 1 & 2 & 3 & $1 / 3$ & & 3 & 5 & $1 / 2$ & 5 & 7 & 1 & 2 & 3 & $1 / 3$ \\
\hline $1 / 3$ & 3 & 1 & 3 & 5 & $1 / 2$ & 1 & $1 / 3$ & $1 / 7$ & & $1 / 3$ & 3 & 1 & 3 & 5 & $1 / 2$ & 1 & $1 / 3$ & $1 / 7$ \\
\hline 5 & 4 & 1 & 3 & 5 & $1 / 3$ & 3 & 1 & $1 / 8$ & & 5 & 4 & 1 & 3 & 5 & $1 / 3$ & 3 & 1 & $1 / 8$ \\
\hline 7 & 9 & 5 & 9 & 7 & 3 & 7 & 8 & 1 & & 7 & 9 & 5 & 9 & 7 & 3 & 7 & 8 & 1 \\
\hline
\end{tabular}

Note that, $C R^{1}=0.091, C R^{2}=0.089, C R^{3}=0.093$ and $C R^{4}=0.093<0.10$.

Note: (1) 9-point scale system: 1 = very low; 3 = low; 5 = moderate; 7 = high; 9 = very high; (2) 2, 4, 6, 8 are intermediate values; (3) [, ] represents rough number and (4) Criteria set: $\left\{\boldsymbol{C}_{\boldsymbol{j}}: \boldsymbol{j}=\mathbf{1}, \mathbf{2}, \ldots, 7\right\}$

Table 4. Aggregated rough comparison matrix

\begin{tabular}{|c|c|c|c|c|c|c|c|c|c|c|c|c|c|c|c|c|c|c|}
\hline & \multicolumn{2}{|l|}{ C1 } & \multicolumn{2}{|l|}{ C2 } & \multicolumn{2}{|l|}{ C3 } & \multicolumn{2}{|l|}{ C4 } & \multicolumn{2}{|l|}{ C5 } & \multicolumn{2}{|l|}{ C6 } & \multicolumn{2}{|l|}{ C7 } & \multicolumn{2}{|l|}{ C8 } & \multicolumn{2}{|l|}{ C9 } \\
\hline & $\mathbf{L}$ & $\mathbf{U}$ & $\mathbf{L}$ & $\mathbf{U}$ & $\mathbf{L}$ & $\mathbf{U}$ & $\mathbf{L}$ & $\mathbf{U}$ & $\mathbf{L}$ & $\mathbf{U}$ & $\mathbf{L}$ & $\mathbf{U}$ & $\mathbf{L}$ & $\mathbf{U}$ & $\mathbf{L}$ & $\mathbf{U}$ & $\mathbf{L}$ & $\mathbf{U}$ \\
\hline C1 & 1.00 & 1.00 & 3.00 & 3.00 & 0.24 & 0.38 & 2.05 & 2.40 & 3.00 & 3.00 & 0.33 & 0.33 & 1.45 & 2.45 & 0.24 & 0.30 & 0.12 & 0.13 \\
\hline $\mathrm{C} 2$ & 0.33 & 0.33 & 1.00 & 1.00 & 0.14 & 0.15 & 0.27 & 0.42 & 0.64 & 0.89 & 0.17 & 0.22 & 0.33 & 0.33 & 0.23 & 0.25 & 0.11 & 0.11 \\
\hline $\mathrm{C3}$ & 1.66 & 4.17 & 6.60 & 6.95 & 1.00 & 1.00 & 3.79 & 4.75 & 5.00 & 5.00 & 2.00 & 2.00 & 1.55 & 2.55 & 1.55 & 2.55 & 0.17 & 0.20 \\
\hline $\mathrm{C4}$ & 0.43 & 0.49 & 2.83 & 4.33 & 0.21 & 0.28 & 1.00 & 1.00 & 5.00 & 5.00 & 0.33 & 0.33 & 0.35 & 0.41 & 0.33 & 0.33 & 0.12 & 0.14 \\
\hline C5 & 0.33 & 0.33 & 1.23 & 1.73 & 0.20 & 0.20 & 0.20 & 0.20 & 1.00 & 1.00 & 0.16 & 0.19 & 0.20 & 0.20 & 0.20 & 0.20 & 0.14 & 0.14 \\
\hline \begin{tabular}{|l} 
C6 \\
\end{tabular} & 3.00 & 3.00 & 4.68 & 5.96 & 0.50 & 0.50 & 3.45 & 4.45 & 5.23 & 6.19 & 1.00 & 1.00 & 2.83 & 4.33 & 3.55 & 4.55 & 0.28 & 0.33 \\
\hline C7 & 0.52 & 0.85 & 3.00 & 3.00 & 0.48 & 0.82 & 2.53 & 2.93 & 5.00 & 5.00 & 0.27 & 0.42 & 1.00 & 1.00 & 0.33 & 0.33 & 0.14 & 0.14 \\
\hline $\mathrm{C8}$ & 3.45 & 4.45 & 4.08 & 4.48 & 0.48 & 0.82 & 3.00 & 3.00 & 5.00 & 5.00 & 0.23 & 0.30 & 3.00 & 3.00 & 1.00 & 1.00 & 0.14 & 0.17 \\
\hline C9 & 7.55 & 8.55 & 9.00 & 9.00 & 5.15 & 5.95 & 7.45 & 8.45 & 7.00 & 7.00 & 3.00 & 3.00 & 7.00 & 7.00 & 5.94 & 7.49 & 1.00 & 1.00 \\
\hline
\end{tabular}

Table 5. Aggregated weights and normalized weights

\begin{tabular}{|l|l|l|l|}
\hline Criteria & Rough weights $\left[\mathbf{W}^{\mathbf{L}}, \mathbf{W}^{\mathbf{U}}\right]$ & Normalized rough weights $\left[\boldsymbol{\omega}^{\mathbf{L}}, \boldsymbol{\omega}^{\mathrm{U}}\right]$ & Criteria rank \\
\hline Cleanliness (C1) & {$[0.7300,0.8650]$} & {$[0.1339,0.1587]$} & 6 \\
\hline Porters (C2) & {$[0.2838,0.3224]$} & {$[0.0520,0.0591]$} & 9 \\
\hline Food (C3) & {$[1.7721,2.2925]$} & {$[0.3250,0.4205]$} & 3 \\
\hline Transportation (C4) & {$[0.5670,0.6412]$} & {$[0.1040,0.1176]$} & 7 \\
\hline Lodging (C5) & {$[0.2919,0.3085]$} & {$[0.0535,0.0566]$} & 8 \\
\hline Rail-fanning (C6) & {$[1.9167,2.2660]$} & {$[0.3515,0.4156]$} & 2 \\
\hline Sightseeing (C7) & {$[0.7905,0.9458]$} & {$[0.1450,0.1735]$} & 5 \\
\hline Safety (C8) & {$[1.2857,1.4974]$} & {$[0.2358,0.2746]$} & 4 \\
\hline Proactively (C9) & {$[5.0856,5.4523]$} & {$[0.9327,1.0000]$} & 1 \\
\hline
\end{tabular}


Now, aggregate the individual judgements using rough numbers from these decision matrices. All the importance ratings are provided in form of linguistic scale. Suppose the set of importance ratings of C3 over C4 is denoted as $\boldsymbol{Z}_{\mathbf{3 4}}=\{$ low, low moderate, moderate $\}=\{3,4,5,5\}$. In order to manipulate the vague and subjective linguistic information in the decision making process, $\boldsymbol{Z}_{\mathbf{3 4}}$ is transformed into the rough number using Equations. (1) to (6). The detailed calculation procedure can be found in Roy et al. (2018). The corresponding rough number is $\overline{\boldsymbol{R N}}\left(\boldsymbol{Z}_{\mathbf{3 4}}\right)=[\mathbf{3 . 7 5}, \mathbf{4 . 7 3}]$. The other rough internal values of criteria functions can be obtained similarly and a rough comparison matrix (Table 4) is formed. Finally, Compute of the criteria weights in rough number by using equations (20)-(21). Finally we normalize those weights according to the equations (22) to get normalized rough number valued weights (Table 5).

\subsection{Implementation of modified rough MABAC}

Rough MABAC is used for ranking the railway station (RS) once the relative weights of the criteria are obtained. Each expert provide a subjective and comprehensive judgment/evaluation to each alternative station based on its criteria under consideration. In order to evaluate the performance of a railway station, the respective judgments of each expert are based on the 9 point scale ranging from "very low" to "very high" for performance evaluation of a railway station, as shown in Table 6. The group decision data originally presented in Table 6 are translated into initial rough decision matrix $\boldsymbol{X}=$ $\left(\left[\boldsymbol{x}_{\boldsymbol{i} j}^{\boldsymbol{L}}, \boldsymbol{x}_{\boldsymbol{i} \boldsymbol{j}}^{\boldsymbol{U}}\right]\right)_{\mathbf{4 0 \times 9}}$ using equations (1) - (6) as done in rough AHP method. Considering the type of the criteria (minimizing type criteria, e.g., cost or maximizing type criteria, e.g., benefit) we first find the values of $\boldsymbol{x}_{\boldsymbol{j}}^{+}$and $\boldsymbol{x}_{\boldsymbol{j}}^{-}$according to equations (26) and (27). Thereafter, normalization of all the data corresponding to initial rough decision matrix are done using equations (24) and (25) and eventually the computation of the normalized rough group decision matrix $\boldsymbol{N}=\left(\left[\boldsymbol{y}_{\boldsymbol{i} \boldsymbol{j}}^{\boldsymbol{L}}, \boldsymbol{y}_{\boldsymbol{i} \boldsymbol{j}}^{\boldsymbol{U}}\right]\right)_{\mathbf{4 0 \times \mathbf { 9 }}}$ is performed. Next, evaluate the weighted rough group decision matrix by multiplying the corresponding normalized weights displayed in Table 5 with the normalized rough group decision matrix using equation (28). Then, apply the geometric aggregation operation for interval valued numbers to border approximation area (BAA) matrix (cf. Table 7) using equation (29) for each evaluation criteria. Using the interval valued Euclidean distance operator [shown in equations (30) and (31)], the distances of the alternative cities from BAA are determined to compute the distance matrix $\boldsymbol{Q}$ as provided in Table 8. Applying equation (32), the closeness coefficients/final score $\boldsymbol{S}\left(\boldsymbol{A}_{\boldsymbol{i}}\right)$ of the alternatives to the ideal/optimal alternative are calculated.

\section{Result and discussion}

In order to obtain better insight from the application of modified rough MABAC in evaluating Indian railway stations, we have investigate the performances of each criterion function for all the alternative stations. In Table 8 , a positive performance value of a station $\left(A_{i}: i=1,2, \ldots, 40\right)$ with respect to a criterion $\left(C_{j}: j=1,2, \ldots, 9\right)$ indicates the goodness of that station. On contrast, a negative performance implies just the opposite event. Similarly, in Figure 2, the stations which have good performance are placed above the horizontal line through origin $(0,0)$; i.e., in the upper approximation area (UAA) whereas, bad performers will fall in the lower approximation area (LAA). According to all the criteria, these figures divide the IR stations into two clusters- good stations which can be found in UAA and bad stations that belong to the LAA with respect to each criterion.

We start with Figure 2(A). Forty proactive railway stations in India are evaluated and ranked by using modified rough MABAC method, and the result shows that the "DMO" is the best compromised optimal choice. Figure 2(A) is plotted with the final performances of those IR stations considering the nine criteria all together. UAA in Figure 2(A) contains 21 stations in UAA, whereas LAA holds rest 19 stations. A deeper observation on Figure 2(A) shows the best stations (DMO), the worst stations (BDTS), and the border line performing station $(\mathrm{BD})$.

Figure 2(B) shows the cleanness performances of forty railway stations in this study. Considering this criterion as benefit/maximizing type, in order to show the potential gain and loss in their performances, Figure 2(B) was drawn based on the performance calculated using the Euclidean distance measure of the alternatives from the border approximation area matrix ("C1" column of Table 8). Seventeen out of forty IR stations are marked as cleaner stations while the other stations are not up to the mark in the viewpoint of cleanness of an IR station. According to Figure 2(B) and Table 8 (cleanness row), the cleaner IR stations are as follow: NDLS, ANVT, BCT, CSTM, HWH, KOAA, VSKP, SC, BEAS, DGR, MCI, RNY, DMO, BHUJ, PURI, CDG, and DWK. Among them MCI, DMO, RNY, and DWK have same highest performance value of 0.098 as cleaner railway stations. Moreover, there are several cleaner stations like, ANVT (0.092), DGR (0.085), BHUJ (0.079), KOAA and SC (both having a 
performance value of 0.068). On the other hand, the individual authority and managing body of stations belonging to the LAA of cleanness $(\mathrm{C} 1)$ need to pay more attention to keep the station clean. Note that, "DLI" is ranked worst station in cleanliness perspective. So, it is extremely suggested that the "DLI" management body should be more attentive to make it a cleaner station.

In a similar manner, we can analyze all the IR stations with respect to each evaluation attribute and determine the potential gainers and losers with respect to that particular attribute (cf. Table 8 and Figs. 2C$2 \mathrm{~J})$. After evaluating the current performance of these stations, we can suggest the stations master/authority to look after necessary changes and improve its performance as a smart railway station. For example, from Table 8, we can directly investigate strength and weakness of each individual IR station. We find that there are few stations (CSTM, VSKP, SC, DMO, and DWK) which have positive performances in every single criterion. So, according to MABAC method (Roy et al., 2018; Xue et al., 2016; Pamučar and Ćirović, 2015; Pamučar et al., 2018), the management of CSTM, VSKP, SC, DMO, and DWK should maintain the present performance. On the other hand, some of the IR stations' (DLI, BDTS, LTT, ANG, MTJ, and MGS) performance are not satisfying in any of those nine criteria. It is recommended that the authorities of these bottom line performers should pay much more attention to improve their services and strictly follow the guidelines of smart railway stations. It is interesting to note that $\mathrm{HWH}$ and $\mathrm{BHUJ}$ have good performances with respect to all criteria except for $\mathrm{C} 2(\mathrm{HWH})$ and $\mathrm{C} 4$ (BHUJ). Apart from these IR stations having bad performances in most of the criteria but are good in a single criterion are NZM (C8), KOAA (C1), LKO (C2), PUNE (C3), GAYA (C7), CNB (C2), and AGC (C3).

Table 6. Expert's opinion based decision matrix

\begin{tabular}{|c|c|c|c|c|c|c|c|c|c|c|c|c|c|}
\hline & \multicolumn{4}{|l|}{$\mathrm{C} 1$} & \multicolumn{4}{|l|}{$\mathrm{C} 2$} & $\cdots$ & \multicolumn{4}{|l|}{ C9 } \\
\hline & 0.30 & 0.25 & 0.25 & 0.20 & 0.30 & 0.25 & 0.25 & 0.20 & $\ldots$ & 0.30 & 0.25 & 0.25 & 0.20 \\
\hline & DM1 & DM2 & DM3 & DM4 & DM1 & DM2 & DM3 & DM4 & $\ldots$ & DM1 & DM2 & DM3 & DM4 \\
\hline NDLS & 6 & 7 & 5 & 7 & 4 & 4 & 6 & 5 & $\ldots$ & 9 & 9 & 8 & 9 \\
\hline DLI & 1 & 1 & 1 & 2 & 3 & 3 & 3 & 4 & $\ldots$ & 5 & 4 & 6 & 6 \\
\hline NZM & 4 & 4 & 3 & 4 & 4 & 4 & 3 & 4 & $\ldots$ & 8 & 8 & 7 & 7 \\
\hline ANVT & 10 & 10 & 9 & 9 & 4 & 4 & 4 & 5 & $\ldots$ & 9 & 8 & 9 & 9 \\
\hline BCT & 6 & 6 & 6 & 7 & 3 & 5 & 3 & 5 & $\ldots$ & 9 & 9 & 9 & 9 \\
\hline BDTS & 4 & 4 & 4 & 4 & 4 & 4 & 4 & 5 & $\ldots$ & 6 & 7 & 6 & 6 \\
\hline LTT & 3 & 3 & 4 & 4 & 5 & 5 & 5 & 4 & $\ldots$ & 5 & 6 & 6 & 5 \\
\hline CSTM & 4 & 6 & 6 & 7 & 6 & 4 & 6 & 5 & $\ldots$ & 9 & 8 & 9 & 9 \\
\hline HWH & 6 & 6 & 7 & 5 & 5 & 5 & 5 & 5 & $\ldots$ & 9 & 9 & 9 & 9 \\
\hline KOAA & 8 & 9 & 8 & 9 & 5 & 4 & 4 & 5 & $\ldots$ & 7 & 8 & 8 & 7 \\
\hline SDAH & 4 & 4 & 4 & 5 & 4 & 5 & 4 & 5 & $\ldots$ & 8 & 8 & 7 & 8 \\
\hline VSKP & 6 & 5 & 7 & 5 & 6 & 6 & 6 & 5 & $\ldots$ & 10 & 10 & 10 & 9 \\
\hline SC & 8 & 8 & 9 & 9 & 10 & 8 & 8 & 9 & $\ldots$ & 10 & 9 & 10 & 10 \\
\hline JAT & 4 & 5 & 5 & 5 & 6 & 6 & 6 & 5 & $\ldots$ & 8 & 9 & 8 & 9 \\
\hline BZA & 6 & 4 & 6 & 5 & 4 & 4 & 6 & 5 & $\ldots$ & 7 & 7 & 8 & 8 \\
\hline LKO & 3 & 4 & 7 & 4 & 6 & 6 & 4 & 5 & $\ldots$ & 8 & 7 & 7 & 7 \\
\hline ADI & 5 & 5 & 5 & 5 & 5 & 5 & 5 & 5 & $\ldots$ & 9 & 7 & 7 & 8 \\
\hline JP & 4 & 4 & 4 & 5 & 6 & 6 & 6 & 5 & $\ldots$ & 9 & 8 & 8 & 9 \\
\hline PUNE & 3 & 5 & 5 & 4 & 4 & 4 & 4 & 5 & $\ldots$ & 7 & 7 & 8 & 8 \\
\hline KSR & 5 & 4 & 3 & 5 & 5 & 6 & 6 & 5 & $\ldots$ & 9 & 9 & 8 & 9 \\
\hline BEAS & 8 & 8 & 8 & 9 & 8 & 8 & 9 & 9 & $\ldots$ & 10 & 10 & 9 & 9 \\
\hline KMT & 5 & 5 & 5 & 5 & 5 & 4 & 4 & 4 & $\ldots$ & 9 & 9 & 9 & 8 \\
\hline ANG & 4 & 6 & 6 & 5 & 4 & 3 & 3 & 4 & $\ldots$ & 6 & 6 & 7 & 7 \\
\hline DGR & 9 & 9 & 10 & 9 & 4 & 4 & 4 & 5 & $\ldots$ & 8 & 8 & 9 & 9 \\
\hline MCI & 10 & 10 & 10 & 9 & 5 & 5 & 5 & 5 & $\ldots$ & 10 & 10 & 10 & 9 \\
\hline $\mathrm{BD}$ & 4 & 4 & 4 & 5 & 6 & 7 & 6 & 5 & $\ldots$ & 8 & 8 & 7 & 9 \\
\hline RNY & 10 & 10 & 10 & 9 & 6 & 6 & 6 & 5 & $\ldots$ & 9 & 9 & 9 & 9 \\
\hline WL & 4 & 6 & 6 & 5 & 4 & 5 & 6 & 5 & $\ldots$ & 8 & 8 & 7 & 9 \\
\hline DMO & 10 & 10 & 10 & 9 & 10 & 9 & 9 & 9 & $\ldots$ & 10 & 10 & 10 & 10 \\
\hline BHUJ & 9 & 9 & 9 & 9 & 8 & 8 & 8 & 9 & $\ldots$ & 9 & 9 & 9 & 10 \\
\hline MAS & 4 & 4 & 5 & 5 & 6 & 6 & 7 & 5 & $\ldots$ & 8 & 9 & 8 & 9 \\
\hline GAYA & 3 & 3 & 4 & 4 & 5 & 5 & 5 & 5 & $\ldots$ & 6 & 6 & 8 & 7 \\
\hline CNB & 3 & 3 & 3 & 4 & 6 & 6 & 6 & 5 & $\ldots$ & 7 & 7 & 6 & 6 \\
\hline MTJ & 3 & 3 & 3 & 4 & 3 & 3 & 3 & 4 & $\ldots$ & 5 & 5 & 6 & 7 \\
\hline AGC & 4 & 4 & 5 & 5 & 4 & 4 & 4 & 5 & $\ldots$ & 8 & 8 & 7 & 7 \\
\hline PURI & 7 & 6 & 6 & 5 & 6 & 5 & 4 & 5 & $\ldots$ & 8 & 8 & 7 & 8 \\
\hline MGS & 4 & 4 & 3 & 4 & 3 & 5 & 4 & 4 & $\ldots$ & 7 & 7 & 6 & 6 \\
\hline CDG & 6 & 6 & 7 & 5 & 5 & 5 & 5 & 5 & $\ldots$ & 9 & 9 & 8 & 8 \\
\hline TVC & 4 & 5 & 6 & 5 & 4 & 4 & 5 & 5 & $\ldots$ & 7 & 7 & 8 & 8 \\
\hline DWK & 10 & 10 & 10 & 9 & 6 & 6 & 6 & 5 & $\ldots$ & 9 & 9 & 10 & 10 \\
\hline
\end{tabular}


Table 7. Border approximation area (BAA) matrix $(\mathrm{G})$

\begin{tabular}{|l|l|l|l|l|l|l|l|l|l|}
\hline & C1 & C2 & C3 & C4 & C5 & C6 & C7 & C8 & C9 \\
\hline G & {$[0.198$,} & {$[0.066$,} & {$[0.433$,} & {$[0.158$,} & {$[0.072$,} & {$[0.505$,} & {$[0.218$,} & {$[0.329$,} & {$[1.457$,} \\
& $0.245]$ & $0.080]$ & $0.595]$ & $0.189]$ & $0.082]$ & $0.649]$ & $0.276]$ & $0.410]$ & $1.657]$ \\
\hline
\end{tabular}

Table 8. Distance of the alternatives from the border approximation area matrix

\begin{tabular}{|c|c|c|c|c|c|c|c|c|c|c|c|}
\hline & C1 & $\mathrm{C} 2$ & C3 & $\mathrm{C} 4$ & $\mathrm{C} 5$ & C6 & C7 & $\mathrm{C} 8$ & C9 & $\Sigma C_{j}$ & Rank \\
\hline NDLS & 0.016 & -0.005 & 0.044 & 0.062 & -0.012 & 0.191 & 0.093 & -0.047 & 0.210 & 0.553 & 12 \\
\hline DLI & -0.102 & -0.023 & -0.137 & -0.050 & -0.012 & -0.097 & -0.009 & -0.036 & -0.703 & -1.169 & 38 \\
\hline NZM & -0.043 & -0.016 & -0.036 & -0.055 & -0.025 & -0.164 & -0.061 & 0.013 & -0.106 & -0.493 & 33 \\
\hline ANVT & 0.092 & -0.011 & 0.072 & 0.050 & -0.012 & -0.044 & -0.033 & -0.091 & 0.210 & 0.234 & 17 \\
\hline BCT & 0.015 & -0.014 & -0.003 & 0.032 & -0.010 & -0.113 & 0.058 & -0.034 & 0.278 & 0.209 & 18 \\
\hline BDTS & -0.039 & -0.011 & -0.185 & -0.056 & -0.024 & -0.252 & -0.119 & -0.129 & -0.437 & -1.250 & 40 \\
\hline LTT & -0.049 & -0.004 & -0.121 & -0.085 & -0.025 & -0.091 & -0.102 & -0.117 & -0.630 & -1.223 & 39 \\
\hline CSTM & 0.009 & 0.004 & 0.084 & 0.050 & 0.007 & 0.212 & 0.084 & 0.008 & 0.210 & 0.668 & 10 \\
\hline HWH & 0.011 & -0.003 & 0.286 & 0.045 & 0.008 & 0.215 & 0.084 & 0.014 & 0.278 & 0.937 & 5 \\
\hline KOAA & 0.068 & -0.007 & -0.036 & -0.049 & -0.012 & -0.044 & -0.031 & -0.007 & -0.113 & -0.231 & 25 \\
\hline SDAH & -0.032 & -0.007 & -0.071 & 0.032 & -0.009 & -0.008 & -0.024 & 0.024 & -0.052 & -0.147 & 23 \\
\hline VSKP & 0.008 & 0.009 & 0.286 & 0.056 & 0.038 & 0.189 & 0.067 & 0.187 & 0.475 & 1.314 & 2 \\
\hline $\mathrm{SC}$ & 0.068 & 0.046 & 0.044 & 0.050 & 0.004 & 0.235 & 0.085 & 0.187 & 0.468 & 1.186 & 3 \\
\hline JAT & -0.020 & 0.009 & -0.006 & -0.013 & 0.004 & -0.009 & 0.085 & 0.171 & 0.140 & 0.360 & 14 \\
\hline BZA & -0.008 & -0.005 & 0.023 & -0.026 & 0.008 & -0.009 & -0.068 & -0.007 & -0.119 & -0.212 & 24 \\
\hline LKO & -0.026 & 0.004 & -0.026 & -0.013 & -0.006 & -0.138 & -0.031 & -0.022 & -0.172 & -0.430 & 31 \\
\hline ADI & -0.016 & -0.003 & -0.028 & -0.013 & 0.004 & -0.098 & 0.004 & -0.050 & -0.072 & -0.272 & 29 \\
\hline JP & -0.032 & 0.009 & -0.006 & -0.038 & -0.012 & 0.212 & 0.070 & -0.019 & 0.146 & 0.330 & 15 \\
\hline PUNE & -0.031 & -0.011 & 0.044 & -0.050 & -0.006 & -0.008 & -0.058 & -0.019 & -0.119 & -0.258 & 26 \\
\hline KSR & -0.031 & 0.005 & -0.048 & 0.044 & 0.039 & 0.166 & 0.085 & -0.092 & 0.210 & 0.378 & 13 \\
\hline BEAS & 0.061 & 0.042 & 0.286 & 0.032 & 0.004 & -0.044 & -0.068 & 0.144 & 0.411 & 0.869 & 7 \\
\hline KMT & -0.016 & -0.010 & 0.023 & 0.056 & 0.038 & 0.210 & -0.031 & 0.157 & 0.217 & 0.644 & 11 \\
\hline ANG & -0.009 & -0.019 & -0.137 & -0.061 & -0.015 & -0.098 & -0.031 & -0.019 & -0.378 & -0.767 & 35 \\
\hline DGR & 0.085 & -0.011 & -0.071 & 0.038 & 0.004 & -0.044 & -0.033 & 0.143 & 0.140 & 0.251 & 16 \\
\hline MCI & 0.098 & -0.003 & -0.095 & 0.038 & 0.039 & -0.008 & 0.078 & 0.157 & 0.475 & 0.777 & 8 \\
\hline BD & -0.032 & 0.012 & 0.044 & 0.057 & 0.003 & -0.025 & -0.068 & -0.007 & 0.043 & 0.027 & 21 \\
\hline RNY & 0.098 & 0.009 & -0.006 & 0.050 & 0.008 & 0.237 & -0.041 & 0.129 & 0.278 & 0.761 & 9 \\
\hline WL & -0.009 & -0.002 & -0.036 & 0.038 & 0.004 & -0.138 & 0.042 & -0.078 & 0.043 & -0.135 & 22 \\
\hline DMO & 0.098 & 0.051 & 0.328 & 0.027 & 0.039 & 0.219 & 0.067 & 0.157 & 0.533 & 1.519 & 1 \\
\hline BHUJ & 0.079 & 0.038 & 0.057 & -0.043 & 0.008 & 0.189 & 0.066 & 0.171 & 0.333 & 0.898 & 6 \\
\hline MAS & -0.026 & 0.012 & 0.098 & 0.033 & -0.022 & -0.045 & 0.058 & -0.050 & 0.140 & 0.197 & 19 \\
\hline GAYA & -0.049 & -0.003 & -0.026 & -0.013 & -0.002 & -0.009 & 0.058 & -0.134 & -0.313 & -0.491 & 32 \\
\hline CNB & -0.055 & 0.009 & -0.046 & -0.056 & -0.002 & -0.098 & -0.068 & -0.034 & -0.365 & -0.715 & 34 \\
\hline MTJ & -0.055 & -0.023 & -0.185 & -0.024 & -0.018 & -0.044 & -0.031 & -0.134 & -0.574 & -1.088 & 37 \\
\hline AGC & -0.026 & -0.011 & 0.059 & -0.025 & -0.002 & -0.044 & -0.059 & -0.050 & -0.106 & -0.264 & 27 \\
\hline PURI & 0.012 & -0.002 & -0.095 & -0.024 & 0.002 & -0.098 & 0.066 & -0.076 & -0.052 & -0.267 & 28 \\
\hline MGS & -0.043 & -0.013 & -0.121 & -0.050 & -0.015 & -0.098 & -0.068 & -0.147 & -0.365 & -0.921 & 36 \\
\hline CDG & 0.011 & -0.003 & 0.072 & 0.044 & -0.009 & -0.187 & 0.067 & -0.019 & 0.152 & 0.128 & 20 \\
\hline TVC & -0.014 & -0.007 & -0.048 & 0.038 & 0.002 & -0.045 & -0.032 & -0.049 & -0.119 & -0.274 & 30 \\
\hline DWK & 0.098 & 0.009 & 0.059 & 0.038 & 0.045 & 0.210 & 0.077 & 0.171 & 0.398 & 1.104 & 4 \\
\hline
\end{tabular}

\section{Comparisons and sensitivity analysis}

In order to present the main advantages of the solution presented with respect to other methods for expressing results, this section will compare and analyse the results obtained with the proposed model for the case study that was explained in Section 3, with the aim of showing the following two aspects:

a) Comparisons with other MCDM methods existing in the literature.

b) Sensitivity analysis of the model to the variation of the weights introduced.

\subsection{Comparisons with other methods}

In order to validate the feasibility and proficiency of the modified rough AHP-MABAC model, a comparative analysis is done on the same example can be performed with some other existing MCDM methods. Some of them are rough AHP-MABAC (Roy et al., 2018), rough AHP-VIKOR (Zhu et al., 2015) and rough TOPSIS (Song et al., 2013). In order to endure a better distinction for the final outcome, the criteria weights determined by the modified rough AHP method in this study are directly incorporated for all the existing MCDM models.

A statistical analysis has been performed to show the efficiency of the proposed method with the rough MABAC and rough VIKOR methods with respect to Spearman rank correlation coefficients as 
0.929 and 0.882 , respectively. However, some of the ranks fluctuate considerably in the rough TOPSIS model with respect to Spearman rank correlation coefficient as 0.772 . The computation steps are not included here since this section is devoted to a comparison of final rankings. It was also noted that, the rank orders of top five railway stations and bottom line stations by the proposed approach are identical to those produced by the MCDM methods, and there is no change in the best-ranked IRS. Station "DMO" enjoys the first place always. This demonstrates the validity of the modified MABAC approach.

Thus, from the above comparison analysis, it can be summarized that the results are compatible to each other and they match moderately to the results of the original ranking order. There are several reasons for applying the MABAC method for this case study. (1) It produces better stable solutions than TOPSIS and VIKOR (Pamučar and Ćirović, 2015); (2) Roy et al. (2018) showed that MABAC method is proactive in analysing qualitative and quantitative data and can classify the alternative solutions as the best, the worst, and borderline performers in a single frame. (3) The MABAC method consists of a comprehensive, rational and sensible algorithmic methodology (Xue et al., 2016). Due to the unique mechanism of MABAC method, it has been widely used in several decision-making aspects (Debnath et al., 2017).
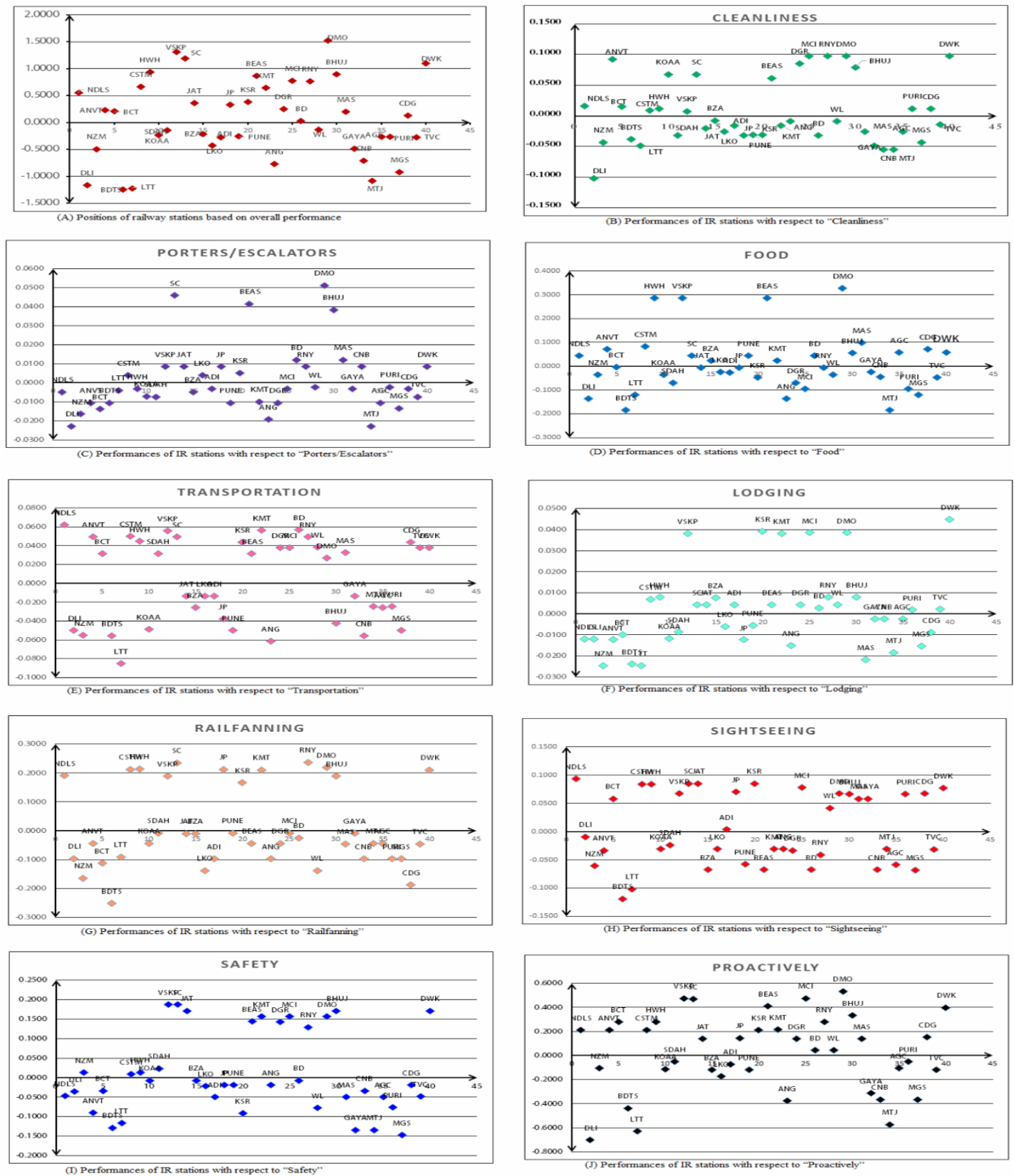

Figure 2. Positions of IR stations in the UAA and LAA based on their performance against all criteria 


\subsection{Sensitivity analysis of the model}

In MCDM, it is convenient to perform sensitivity analysis in order to test the stability of the proposed framework and the final ranking. A large number of sensitivity analyses are performed due to a slight variation in the criteria relative weights (Debnath et al., 2017). Relative weights of some criteria are increased and some of them are decreased according to Eq. (32).

$w_{j}^{\text {new }}=w_{j}^{\text {old }} \pm \alpha w_{j}^{\text {old }}$

where $\alpha$ is the percentage change of $\boldsymbol{w}_{\boldsymbol{j}}^{\text {old }}$. As original weights, the total new sum is also kept to unity, i.e. $\sum_{j=1}^{n} \boldsymbol{w}_{j}^{n e w}=\mathbf{1}$. In this work, the criteria weights are calculated by means of linguistic inputs. Thus, the robustness testing has been conducted by assigning modified weights of the criteria for evaluating and selecting most preferable IR stations. This also benefits to crisscross the reliability in decision making. Small changes in criteria weights have a little effect on the final ranking of the aforementioned forty IR stations. Outcomes of the sensitivity analysis endorse that either DMO or VSPM or DWK are best among the top 40 stations of IR. From Table 9, we observe several changes in the ranking order if the criteria weights undergo huge changes. Additionally, "DMO" have top ranking in maximum number of scenarios except in scenario 6 and 8. In these two cases, a drastic change in priorities of 'all criteria' (cf. Table 9) have been observed with a big change in IRS ranking. Such actions affect the final ranking and "VSKP" is promoted to the highest ranking followed by $\mathrm{DMO}, \mathrm{SC}, \mathrm{DWK}$, and $\mathrm{HWH}$ for top five Indian railway station in such scenarios. Briefly speaking, the ranking remains consistent unless some drastic changes are made in the weights of criteria set. Otherwise, sensitivity analysis shows robustness in ranking order (cf. Table 9) of alternative Indian railway station in this case study. Either DMO or VSKP or DWK enjoy top two ranks in all scenarios and may be selected as best by the decision makers. At the end, the sensitivity analysis may be meaningful to assess the Indian railway station as alternative options while promoting IRs development.

Table 9. Rank of the stations in various scenarios

\begin{tabular}{|c|c|c|c|c|c|c|c|c|c|}
\hline & 焉晨 & 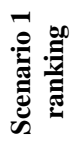 & 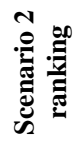 & 串 & 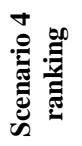 & 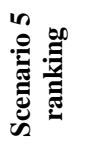 & 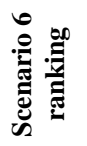 & م祭 & 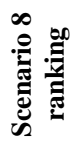 \\
\hline NDLS & 12 & 12 & 12 & 13 & 12 & 12 & 12 & 13 & 12 \\
\hline DLI & 38 & 39 & 39 & 36 & 38 & 39 & 39 & 36 & 38 \\
\hline NZM & 33 & 33 & 33 & 34 & 33 & 33 & 33 & 34 & 33 \\
\hline ANVT & 17 & 17 & 17 & 18 & 17 & 17 & 17 & 18 & 17 \\
\hline BCT & 18 & 18 & 18 & 19 & 18 & 18 & 18 & 19 & 18 \\
\hline BDTS & 40 & 38 & 38 & 37 & 40 & 38 & 38 & 37 & 40 \\
\hline LTT & 39 & 40 & 40 & 38 & 39 & 40 & 40 & 38 & 39 \\
\hline CSTM & 10 & 10 & 10 & 11 & 10 & 10 & 10 & 11 & 10 \\
\hline HWH & 5 & 4 & 4 & 4 & 5 & 4 & 4 & 4 & 5 \\
\hline KOAA & 25 & 25 & 25 & 26 & 25 & 25 & 25 & 26 & 25 \\
\hline SDAH & 23 & 23 & 23 & 24 & 23 & 23 & 23 & 24 & 23 \\
\hline VSKP & 2 & 3 & 3 & 3 & 2 & 3 & 1 & 3 & 1 \\
\hline SC & 3 & 2 & 2 & 5 & 3 & 2 & 3 & 5 & 2 \\
\hline JAT & 14 & 14 & 14 & 15 & 14 & 14 & 14 & 15 & 14 \\
\hline BZA & 24 & 24 & 24 & 25 & 24 & 24 & 24 & 25 & 24 \\
\hline LKO & 31 & 31 & 31 & 32 & 31 & 31 & 31 & 32 & 31 \\
\hline ADI & 29 & 29 & 29 & 30 & 29 & 29 & 29 & 30 & 29 \\
\hline JP & 15 & 15 & 15 & 16 & 15 & 15 & 15 & 16 & 15 \\
\hline PUNE & 26 & 26 & 26 & 27 & 26 & 26 & 26 & 27 & 26 \\
\hline KSR & 13 & 13 & 13 & 14 & 13 & 13 & 13 & 14 & 13 \\
\hline BEAS & 7 & 7 & 7 & 8 & 7 & 7 & 7 & 8 & 7 \\
\hline KMT & 11 & 11 & 11 & 12 & 11 & 11 & 11 & 12 & 11 \\
\hline ANG & 35 & 35 & 35 & 36 & 35 & 35 & 35 & 36 & 35 \\
\hline DGR & 16 & 16 & 16 & 17 & 16 & 16 & 16 & 17 & 16 \\
\hline MCI & 8 & 8 & 8 & 9 & 8 & 8 & 8 & 9 & 8 \\
\hline $\mathrm{BD}$ & 21 & 21 & 21 & 22 & 21 & 21 & 21 & 22 & 21 \\
\hline RNY & 9 & 9 & 9 & 10 & 9 & 9 & 9 & 10 & 9 \\
\hline WL & 22 & 22 & 22 & 23 & 22 & 22 & 22 & 23 & 22 \\
\hline DMO & 1 & 1 & 1 & 1 & 1 & 1 & 2 & 1 & 3 \\
\hline BHUJ & 6 & 6 & 6 & 7 & 6 & 6 & 6 & 7 & 6 \\
\hline
\end{tabular}




\begin{tabular}{|l|c|c|c|c|c|c|c|c|c|}
\hline MAS & 19 & 19 & 19 & 20 & 19 & 19 & 19 & 20 & 19 \\
\hline GAYA & 32 & 32 & 32 & 33 & 32 & 32 & 32 & 33 & 32 \\
\hline CNB & 34 & 34 & 34 & 35 & 34 & 34 & 34 & 35 & 34 \\
\hline MTJ & 37 & 36 & 36 & 39 & 37 & 36 & 36 & 39 & 37 \\
\hline AGC & 27 & 27 & 27 & 28 & 27 & 27 & 27 & 28 & 27 \\
\hline PURI & 28 & 28 & 28 & 29 & 28 & 28 & 28 & 29 & 28 \\
\hline MGS & 36 & 37 & 37 & 40 & 36 & 37 & 37 & 40 & 36 \\
\hline CDG & 20 & 20 & 20 & 21 & 20 & 20 & 20 & 21 & 20 \\
\hline TVC & 30 & 30 & 30 & 31 & 30 & 30 & 30 & 31 & 30 \\
\hline DWK & 4 & 3 & 3 & 2 & 4 & 3 & 3 & 2 & 4 \\
\hline
\end{tabular}

\section{Conclusions}

In the present work, firstly, the rough AHP-MABAC model (Roy et al., 2018) is modified by incorporating the hierarchical preferences among the decision makers in a practical group decision making problem. The subjective judgments of the expert's while assessing the relative priorities of evaluation criteria and the performance of each individual alternative are expressed linguistically. Then, these linguistic ratings are converted to their corresponding rough numbers using rough aggregation rules. Next, we propose an evaluation framework called modified rough AHP-MABAC for prioritizing the IRS based on their performances. On implementing this evaluation model several insights are found, and from the final outcomes, the most successful IR station(s) are listed according to their performances. The major contributions of this paper could be summarized as follow:

- Development of a hierarchical and methodological procedure with step-wise derivation dealing with vague and subjective information in an MCDM, applied to evaluate the IR stations.

- The modified rough AHP-MABAC method consists of a comprehensive, rational and sensible algorithmic methodology.

- Enlightening the overall performances with a quantitative analysis which help in classifying both the best, the worst, and borderline performers (stations) in IR system (Fig. 2).

- A flexible multi-criteria decision making (MCDM) framework that can also be applied to other MCDM problems irrespective of the case study.

- This ranking method will enable IR station managers, IR administration and policy makers in governing the IR system to the global standards with proper evaluation and prioritization.

Though the proposed research framework serves well and produces satisfactory results, some limitations still exist. Only nine evaluation criteria and top forty IR stations have been considered in this study. There are cases where an individual criterion will be affected by many sub-criteria and mostly those sub-criteria are influential and correlated with each other. In future, studies related to retiring rooms and waiting rooms of Indian railways can be conducted with some data mining techniques or by some alternate MCDM methods under some diverse uncertain (fuzzy, fuzzy random, rough) environments. The aggregation operators influence on rough AHP-MABAC would also be exposed in future research.

\section{Acknowledgments}

The second author extends his sincere thanks to the Department of Science and Technology, India for their financial support under INSPIRE Fellowship program with the research grant no. DST/INSPIRE Fellowship/2013/544.

\section{References}

1. Brons, M., Givoni, M., and Rietveld, P. (2009) Access to railway stations and its potential in increasing rail use. Transportation Research Part A, 43, pp. 136-149.

2. Chen, C.T. (2000) Extensions of the TOPSIS for group decision-making under fuzzy environment. Fuzzy sets and systems, 114(1), pp. 1-9.

3. Daamen, W. (2002) A quantitative assessment on the design of a railway station. WIT Transactions on the Built Environment, 61.

4. Debnath, A., Roy, J., Kar, S., Zavadskas, E.K. and Antucheviciene, J. (2017) A Hybrid MCDM Approach for Strategic Project Portfolio Selection of Agro By-Products. Sustainability, 9(8), pp. 1302. 
5. Givoni, M. and Rietveld, P. (2007) The access journey to the railway station and its role in passengers' satisfaction with rail travel, Transport Policy 14, pp. 357-365.

6. Givoni, M. and Rietveld, P. (2014) Do cities deserve more railway stations? The choice of a departure railway station in a multiple-station region, Journal of Transport Geography, 36, pp. 8997.

7. Hennig, C., Meila, M., Murtagh, F. and Rocci, R. (2015) Handbook of cluster analysis. CRC Press.

8. Kaakai, F., Hayat, S. and Moudni, A. E. (2007) A hybrid Petri nets-based simulation model for evaluating the design of railway transit stations. Simulation Modelling Practice and Theory, 15, pp. 935-969.

9. Khoo, L.P. and Zhai, L.Y. (2001) A prototype genetic algorithm-enhanced rough set-based rule induction system. Computers in Industry, 46(1), pp. 95-106.

10. Lai, W.T. and Chen, C. F. (2011) Behavioral intentions of public transit passengers-The roles of service quality, perceived value, satisfaction and involvement. Transport Policy, 18, pp. 318-325.

11. Liang, H., Ren, J., Gao, Z., Gao, S., Luo, X., Dong, L. and Scipioni, A. (2016) Identification of critical success factors for sustainable development of biofuel industry in China based on grey decision-making trial and evaluation laboratory (DEMATEL). Journal of Cleaner Production, 131, pp. 500-508.

12. Martínez, L., Liu, J., Ruan, D. and Yang, J.B. (2007) Dealing with decision-making information in engineering evaluation processes. Information Sciences, 177(7), pp. 1533-1542.

13. Mateus, R., Ferreira, J. A. and Carreira, J. (2008) Multicriteria decision analysis (MCDA): Central Porto high-speed railway station. European Journal of Operational Research, 187, pp. 1-18.

14. Mohajeri, N. and Amin, G. R. (2010) Railway station site selection using analytical hierarchy process and data envelopment analysis. Computers \& Industrial Engineering, 59, pp. 107-114.

15. Pamučar, D. and Ćirović, G. (2015) The selection of transport and handling resources in logistics centers using Multi-Attributive Border Approximation Area Comparison (MABAC). Expert Systems with Applications, 42(6), pp. 3016-3028.

16. Pamučar, D., Petrovic, I. and Ćirović, G. (2018) Modification of the Best-Worst and MABAC methods: A novel approach based on interval-valued fuzzy-rough numbers, Expert Systems with Applications, 91, pp. 89-106.

17. Pawlak, Z. (1982) Rough sets. International Journal of Parallel Programming, 11(5), pp. 341356.Zh

18. Pawlak, Z. (1991) Rough Sets. Theoretical aspects of reasoning about data. Kluwer Academic Publishers, Dordrecht.

19. Qazi, K.I., Lam, H.K., Xiao, B., Ouyang, G. and Yin, X. (2016) Classification of epilepsy using computational intelligence techniques. CAAI Transactions on Intelligence Technology, 1(2), pp. 137-149.

20. Rietveld, P. (2000). The accessibility of railway stations: the role of the bicycle in The Netherlands, Transportation Research Part D, 5, pp. 71-75.

21. Roy, J., Adhikary, K. and Kar, S. (2016a) Credibilistic TOPSIS Model for Evaluation and Selection of Municipal Solid Waste Disposal Method. ArXiv preprint, URL: http://arxiv.org/abs/1607.01254.

22. Roy, J., Chatterjee, K., Bandyopadhyay, A. and Kar, S. (2018) Evaluation and selection of medical tourism sites: A rough analytic hierarchy process based multi-attributive border approximation area comparison approach. Expert Systems, 35(1), DOI: https://doi.org/10.1111/exsy.12232

23. Roy, J., Ranjan, A., Debnath, A. and Kar. S. (2016b) An extended MABAC for multi-attribute decision making using trapezoidal interval type-2 fuzzy numbers. ArXiv preprint, URL: http://arxiv.org/abs/1607.01254

24. Saaty, T.L. and Vargas, L.G. (2012) Models, methods, concepts \& applications of the analytic hierarchy process (Vol. 175). Springer Science \& Business Media.

25. Song, W., Ming, X. and Wu, Z. (2013) An integrated rough number-based approach to design concept evaluation under subjective environments. Journal of Engineering Design, 24(5), pp. 320341.

26. Wang, H., Yang, B. and Chen, W. (2016) Unknown constrained mechanisms operation based on dynamic interactive control. CAAI Transactions on Intelligence Technology, 1(3), pp. 259-271.

27. Zheng, P., Xu, X. and Xie, S.Q. (2016) A weighted interval rough number based method to determine relative importance ratings of customer requirements in QFD product planning. Journal of Intelligent Manufacturing, pp. 1-14. DOI: https://doi.org/10.1007/s10845-016-1224-z 
28. Xue, Y.X., You, J.X., Lai, X.D. and Liu, H.C. (2016) An interval-valued intuitionistic fuzzy MABAC approach for material selection with incomplete weight information. Applied Soft Computing, 38, pp. 703-713.

29. Zemp, S., Stauffacher, M., Lang, D.J. and Scholz, R.W. (2011) Classifying railway stations for strategic transport and land use planning: Context matters. Journal of Transport Geography, 19, pp. 670-679.

30. Zhai, L.Y., Khoo, L.P. and Zhong, Z.W. (2008) A rough set enhanced fuzzy approach to quality function deployment. The International Journal of Advanced Manufacturing Technology, 37(5-6), pp. 613-624.

31. Zhai, L.Y., Khoo, L.P. and Zhong, Z.W. (2009) A rough set based QFD approach to the management of imprecise design information in product development. Advanced Engineering Informatics, 23(2), pp. 222-228.

32. Zhai, L.Y., Khoo, L.P. and Zhong, Z.W. (2010) Towards a QFD-based expert system: A novel extension to fuzzy QFD methodology using rough set theory. Expert Systems with Applications, 37(12), 8888-8896.

33. Zhu, G. N., Hu, J., Qi, J., Gu, C.C. and Peng, Y.H. (2015) An integrated AHP and VIKOR for design concept evaluation based on rough number. Advanced Engineering Informatics, 29(3), pp. 408-418. 